\title{
Letters
}

Website: bmj.com

Email: letters@bmj.com

\section{Racism in medicine}

\section{Regional arbitration panel may offer solution}

EDITOR-I applaud Bhopal for writing the truth about what each one of us has to face, personally and professionally during service in the NHS. ${ }^{1}$ It is time we all recognised that covert and overt racist practices occur within the NHS, and there needs to be an immediate arbitration panel in each region that can resolve issues speedily and hear both sides of disputes independently.

The Canadians have such a model, and it has been extremely effective in minimising, almost excluding, any racist practices in the health environment. I am from a family of doctors who have worked in the NHS for over 60 doctor years. Each one of us has suffered discrimination. I have always tried to place the personal insults behind me, hoping that my personal and professional abilities would show through. At junior level there was mutual tolerance. The transient nature of work provided relief without the need to speak out. But once I became a consultant, I experienced such gross discrimination that I was forced to resign (only $8 \%$ of consultant posts are staffed by doctors of non-white ethnic origin, and even fewer, $2.4 \%$, are staffed by non-white women). Not

\section{Advice to authors}

We prefer to receive all responses electronically, sent directly to our website. Processing your letter will be delayed unless it arrives in an electronic form.

We are now posting all direct submissions to our website within 24 hours of receipt and our intention is to post all other electronic submissions there as well. All responses will be eligible for publication in the paper journal.

Responses should be under 400 words and relate to articles published in the preceding month. They should include $\leqslant 5$ references, in the Vancouver style, including one to the BMJ article to which they relate. We welcome illustrations.

Please supply each author's current appointment and full address, and a phone or fax number or email address for the corresponding author. We ask authors to declare any competing interest. Please send a stamped addressed envelope if you would like to know whether your letter has been accepted or rejected.

Letters will be edited and may be shortened.

bmj.com

letters@bmj.com one person in the trust I worked for thanked me or apologised. The illegal manoeuvres within employment laws were overlooked. I felt the only path open to me was through legal channels but found the legal arena of little help despite the race relations and human rights law. The NHS and those within it collude, have unlimited access to finance, and bring witnesses who are coached to commit perjury. The legal profession is no better; there is plenty of evidence for their institutional racism.

If doctors from an ethnic group speak out, they are seen as difficult, their jobs are placed at risk (which is reflected in references), or they are classified as psychologically unstable, thus victimised for standing up for justice and inducing fear in those who stand by and do nothing. We want to get on with our jobs, feel happy, and fulfil our potential. We are not just workhorses here: we should be given equal rights in the workplace. Someone should take heed and provide a path to quick resolution of any discriminatory incident, so that anger, hurt, insecurity, and discrimination can become history.

B R Pal consultant neonatologist (locum) Department of Women's and Child Health, University Hospitals Coventry and Warwickshire Coventry CV2 2DX BRPal@fsmail.net

\section{Bhopal R. Racism in medicine. BMJ 2001;322:1503-4. (23 June.)}

\section{We need action, not more evidence}

EDITOR-That racism is deeply entrenched in the NHS is obvious to anyone who cares to see. It does not need more and more evidence as the apologists of institutional racism in the NHS establishment insist, it needs action. Racism does not take the form now that Bhopal experienced as a junior doctor. ${ }^{1}$ It is, however, still pervasive, not all that subtle, and very effective at ruining the career of the people at the receiving end, but it does not take a verbal form.

When I came over to the United Kingdom, despite possessing a postgraduate degree in medicine from India and having passed the first part of the examination to become a member of the Royal College of Physicians, I did not get a single interview for a post as a senior house officer in medicine, not even a locum post, although I wrote hundreds of applications. It was only after I had passed the second part of the royal college's examination that I got my first job in medicine.
Later on in my career, despite good clinical experience in medicine and my specialty and good academic credentials (a research degree from a British university and a few publications in eminent journals), I applied for every single job as a senior registrar in my specialty for three years without getting a single interview. This was at a time when the job market in my specialty was actually quite favourable. But I had no chance until every possible home grown graduate (usually white), however inferior his curriculum vitae to mine, had a job and was not in competition.

One kind consultant wrote to the person then in charge of postgraduate medical education and training in England about me, inquiring why I was not moving up the ladder. His contribution was that he was surprised at my lack of progress and that he would be able to help if I changed my specialty and went into geriatrics. I treated his advice with a certain amount of contempt. I did eventually get a senior registrar job in my specialty, but that was purely through chance as I happened to come in contact with some very straight and fair minded consultants while doing a locum consultant job.

My experience is not unique. The NHS is harming itself by condoning, tolerating, and encouraging institutional racism. It is depriving itself of calibre and promoting a culture of mediocrity.

Pradip Singh consultant gastroenterologist Staffordshire General Hospital, Stafford ST16 3SA psingh56@doctors.org.uk

1 Bhopal R. Racism in medicine. BMJ 2001;322:1503-4. (23 June.)

\section{Institutional racism in the $B M J$ ?}

Editor-I was delighted to see that the important new book from the King's Fund on racism in medicine received good coverage in the $B M J$, with a news feature and an editorial giving examples of casual racism during the author's career, as well as further coverage in Editor's choice. ${ }^{1-4} \mathrm{I}$ was therefore astonished that you chose to publish in the same issue a list of terms used in job advertisements with facetious translations, including "interesting and varied case mix" "translated" as "half of the patients do not speak English," and "multicultural environment" as "neither do the staff."

The report of the Stephen Lawrence inquiry defined institutional racism as the collective failure of an organisation to provide an appropriate and professional service to people because of their colour, culture, or ethnic origin and pointed out 
that this may occur through unwitting prejudice, ignorance, or thoughtlessness. There could hardly be a better example of this than the publication of this letter. Sanctimonious editorials are not enough. If you are going to talk the talk, you should walk the walk. Otherwise we may not believe that you actually care that medicine is behind some other sectors in exorcising racism.

Paula McDonald consultant in communicable disease control

Communicable Disease Unit, Chester

Paula@coltonhouse.freeserve.co.uk

1 Coker N, ed. Racism in medicine: an agenda for change. London. King's Fund, 2001.

2 Gulland A. Ethnic minority doctors hit glass ceiling in NHS. BMI 2001;322:1505. (23 June.)

3 Bhopal R. Racism in medicine. BMJ 2001;322:1503-4. (23 June.)

4 Editor's choice. Apoptosis and racism: a long time coming and a long time going. BMJ 2001;322 (7301). (23 June.) 5 Campbell C. Job advertisements. BMJ 2001;322:1547. (23 June.)

\section{Environment for open, constructive debate is needed}

EDITOR-We are a female physician who has grown up in the United Kingdom and a male sociologist in medical training in the United States, both of Indian origin. We are compelled to comment on the current debate about racism in the NHS. We wonder whether the lack of progress made is related to the failure to create an environment in which we can have constructive and open debate. There is clearly racism in the NHS and other institutions, but racism cannot be considered as an isolated issue as we have both experienced different forms of discrimination outside of race. ${ }^{12}$ This has often been at the hands of men from ethnic minority groups who want equality for themselves on the basis of race but are unprepared to give the same courtesy to others with differences.

As Bhopal says in his editorial, antiracism is best seen as a component of the struggle against oppression. ${ }^{3}$ Until we do that and work towards creating equality on all fronts (including sex, age, religion, disability, and sexual orientation), each group of minority or vulnerability will forward its own case without necessarily leading to the kind of broad culture in which equality is a given. However much we may try to separate out these forms of discrimination, they are interlinked at an institutional and societal level.

At Leicester University the component on race and cultural diversity of the human diversity module (other components include sexuality and gender, religion, and disability) has been shown to be effective in helping students to address personal prejudices early and start challenging their views of all kinds of people. ${ }^{4}$ There is a need to acknowledge that we all have prejudicial views of one sort or another before the impact of these views on professional practice can be addressed. A key to the success of this module has been the willingness of staff to broach sensitive issues and engage students in such a crucial dialogue. In the module, cultural awareness is not about denigrating the majority perspective, but about learning that we all need to have an awareness and sensitivity to cultures different from our own.

There is clearly a need for debate and action, at all levels, including personal and organisational. It is, however, important not to oversimplify the complexity of institutional oppression by focusing exclusively on one strand of this process.

Nisha Dogra senior lecturer in child and adolescent psychiatry

nd13@leicester.ac.uk

Niranjan Karnik visiting fellow

Greenwood Institute of Child Health, University of Leicester, Leicester LE3 0QU

1 Coker N. Racism in medicine: an agenda for change. London. King's Fund, 2001

2 Carvel J. Secret government report finds racism flourishing in NHS. Guardian 2001 June 25;A1:4

3 Bhopal R. Racism in medicine. BMJ 2001;322:1503-4. (23 June.)

4 Dogra N. The development and evaluation of programme to teach cultural diversity to medica undergraduate students. Med Educ 2001;35:232-41.

\section{Everyone should be treated with respect and dignity}

EDITOR-The NHS is not racist. Bhopal and most of the electronic respondents describing their experiences of working in the NHS do not have the experience of not being black. ${ }^{1}$ Except for comments made specifically about colour or race, they have been on the receiving end of horrible behaviour that most doctors have encountered.

I worked with a consultant who would not shake my hand when I initially introduced myself, theatre staff who despised me, an outpatient sister who turned against me because I did not respond to her flirtations, paramedical staff who badmouthed me to patients, and unhelpful and obstructive ward staff. In one post colleagues ostracised me for two years because I was promoted ahead of them, which they believed was because I was white and they were Asian (they also conducted a vendetta against the doctor who was promoted to acting head of the department; he was Asian). I have not been shortlisted for jobs I thought I was suitable for, not got jobs when I thought I was the best candidate, and the list goes on.

But I may not have been the best candidate, or the interviewers were looking for someone with different skills, or my behaviour or attitude may have engendered some of the hostility that I faced. This isn't "blaming the victim," but I didn't see the curricula vitae of the other candidates who applied, and I have some responsibility in interpersonal relationships.

The NHS is staffed by imperfect people, many of whom have important needs of their own. Paradoxically in the caring professions, these people try to ameliorate their needs at the expense of colleagues and patients. Some prejudices (preconceived opinions of an individual based on opinions about the many) have names-such as racism, sexism, or ageism. Other neologisms could be doctorism, surgeonism, or obstetricianism. These are only descriptions of unpleasant, unassertive, dishonest, or unprofessional attitudes.

A sign in one waiting room said, "We promise to treat you with respect and dignity irrespective of your race, age, sex, gender, or sexual orientation." Why not treat everyone with respect and dignity, irrespective of anything? Prejudice of all types must be challenged, firstly, within ourselves and, secondly, by people at every level of every discipline. Derogatory generalisations reflect prejudices that are unacceptable in all walks of life but especially in the caring professions and especially by those who are in positions of authority and influence.

Charles Essex consultant neurodevelopmental paediatrician

Child Development Unit, Gulson Hospital, Coventry CV1 2HR

1 Bhopal R. Racism in medicine. BMJ 2001;322:1503-4. (23 June.)

\section{Evidence base is needed}

EDITOR-Like Dadabhoy, who was quoted in Gulland's news item on ethnic minority doctors and the glass ceiling in the NHS, I am a general practitioner. ${ }^{1}$ Like him, while a junior doctor, I explored the possibilities of a specialist career but made very little progress.

I could try to claim that this was because I was a man from Northern Ireland working in the south of England, but the truth was otherwise. My consultants recognised that I was temperamentally unsuited to the life of a general surgeon and that I could not lay claim to above average physical dexterity. Also I have to admit that I was rather slow in shedding some rather adolescent personality characteristics. (Indeed, the fact that I embarked on posts as a surgical senior house officer was prompted by a temporary period of concern, soon after I qualified, about whether I could manage to get satisfaction from looking after people with chronic disorders who were not going to get better. In general surgery the contact with the patient seemed more decisive, and more limited, and more glamorous.)

I have now been in general practice for 20 years; although I often feel overworked, quite often frustrated, and occasionally simply frightened, my life is free of boredom and I enjoy a good income. I trust the outcome for Dadabhoy has been as satisfactory.

The period of surgical involvement has stood me in good stead in several ways. A particular stroke of luck while I was doing a course for the final examination to become a fellow of the Royal College of Surgeons was meeting a female registrar recently arrived from India. We became friends, and, after a couple of years, she agreed to marry me. I do not believe that her rise to her current rank of professor in her specialty was greatly delayed by her being Indian.

Like Bhopal, your editorialist (who I note in passing has also reached the rank of professor), I am all for extirpating racism in medicine, if it can be found. ${ }^{2}$ Neither the news item nor the editorial contain much 
more than anecdotes. The medical profession may have to admit to being chronically, hopelessly institutionally racist, and if so, then our antagonists in government and the press will have another stick with which to beat us. But if we are going to adopt a self lacerating stance on this issue, can we not at least have evidence based self laceration?

J V R Barbour principal general practitioner Springvale Group Practice, 63 Springfield Road, Belfast BT12 7DN

1 Gulland A. Ethnic minority doctors hit glass ceiling in NHS. BMJ 2001;322:1505. (23 June)

2 Bhopal R. Racism in medicine. BMJ 2001;322:1503-4. (23 June.)

\section{Author's summary of responses}

EDITOR-The issue of racism in medicine sparks interest and passion, as testified by nearly 6000 internet hits, over 40 rapid responses, ${ }^{1}$ about 10 personal letters to me, and at least five newspaper articles in response to my editorial. I predicted that some hearts would sink at the article, but I judge that more spirits rose than sank.

Comment fell into four unequal categories.

(1) The majority view was that there is indeed pervasive racism in medicine and it is right to open up the issue. The testimony in the letters, together with that already in the landmark book from the King's Fund and in earlier writings, ${ }^{2}$ points to the anger, frustration, and hurt caused by injustices perceived as arising from racism.

(2) A substantial viewpoint was that there is a problem but it should be kept in perspective because either progress is being made or the position is better than in other countries. Although this may be true, such arguments could impede progress.

(3) An important but minority view was that racism is innate or inevitable ("Chin up, guys," says Menezes).

(4) Hostility to the principles and specific proposals in my editorial was rarely expressed. The crucial, and perhaps, unanswerable question is whether those who are hostile are disinclined to respond. Abbott defended the institutions of "those natives whose ancestral DNA is buried in the soil of these islands" against being labelled racist, blamed illegal residents for draining the NHS, and suggested that those legally in this country "bother to learn English." (My mother's English remained broken, despite her passion for education, which was fulfilled through her children, seven of whom graduated from university.)

The dialogue must continue, and there is much to be gained from examining the spectrum of opinion. Abbott's indignance, Morrell's scholarly stance, and the cries for justice from most correspondents, all have a place as we merge research and opinion and work to free the world from the grip of racism. Overall, most people now seem to accept we have a problem-the key step to a solution.

Raj Bhopal professor of public health Department of Community Health Sciences, Public Health Sciences, University of Edinburgh, Edinburgh EH8 9AG
1 Electronic responses. Racism in medicine. bmj.com 2001;322 (www.bmj.com/cgi/eletters/322/7301/1503; accessed 1 Nov 2001).

2 Coker N, ed. Racism in Britain: an agenda for change. London: King's Fund, 2001

\section{Equity in the new NHS}

\section{Small groups should not undertake responsibilities on their own}

EDITOR-Doyle's refreshing article describes the daily realities of priority setting faced by commissioning bodies. ${ }^{1}$ The article also provides a welcome counterbalance to the unrealistic hype over the National Institute for Clinical Excellence (NICE) being hailed as rational decision making in the NHS and the answer to postcode prescribing.

Commissioners are given the task of making difficult funding decisions in a politically and socially ambigious milieu. In undertaking this task I give caution over the practice of agreeing exceptions on compassionate grounds. I support Doyle's suggestion that this is often a means to bypass the evidence. It is often seen as a useful tool to avoid getting caught over the "never say never" directive. This is because agreeing some exceptions shows that the organisation does not "fetter its discretion" (the term for this type of transgression by public bodies).

There is much to recommend expressing compassion in the NHS-we all expect it-and I do not undervalue the collective benefit gained from the belief that this expectation will be met. But what does "accepting on compassionate grounds" mean in the context of resource allocation? We have grappled with this locally and have come to the conclusion that all too often it means agreeing funding for those who shout loudest.

Furthermore, you can also find yourself in darker waters. Exceptional reasons presented to us often include keeping a person in employment, being a mother, being comparatively young, etc. A decision made on the basis of an exception may therefore come down to defining the worth of an individual to society or applying an arbitrary hierarchy of tragic circumstance. These are not the kind of decisions I am comfortable making, for all sorts of reasons, not the least of which is some notion of equality. I also find it uncomfortable to dress value judgments up as pseudoclinical decisions to make a decision more palatable. I have seen this happen at all levels of the NHS over the years. I recommend avoiding doing both of these things.

Both as citizen and public health professional I am willing to participate in priority setting processes and see it as a responsibility. But the current situation of having small groups of people bear much of the burden of value based decisions is a reflection that society continues to bury its head in the sand, thereby abdicating from a key responsibility. While this is understandable, I fear that commissioners are all too quickly and conveniently cast in the role of scapegoat as a result.

Daphne Austin consultant in public health Worcestershire Health Authority, Worcester WR4 9RW

Daphne.Austin@wha.worcester-ha.wmids.nhs.uk

1 Doyle Y. Equity in the new NHS: hard lessons from implementing a local healthcare policy on donepezil. $B M$ 2001;322:222-4. (28 July.)

\section{Evidence cannot help in all situations}

EDitoR-I was one of the prescribers of donepezil for a patient in Merton, Sutton, and Wandsworth while that health authority maintained its refusal to fund its NHS prescription. Doyle gives a glimpse into the authority's reasoning and approach. ${ }^{1}$ She gives the impression of a rational, evidence based purchasing organisation surprised, and aggrieved, at the apparent triumph of public emotion over reason.

The idea-supported by Austin in her electronic response (www.bmj.com/cgi/ eletters/323/7306/222\#EL4; letter above) -that something called "compassionate" use of the drug might be viewed as a way around the evidence is astonishing. All good medical practice is founded on compassion, an emotional response to distress in patients or carers. The decision to prescribe is based on this emotion, but using evidence as a tool-in this case to help us decide on the ratio of benefit to risk of not treating versus treating. It seemed obvious from the evidence that the average "modest" benefit of donepezil was likely to be a net result in a mixture of good and poor responders, and no one knew (or yet knows) who was who.

Given the evidence, prescribing is the evidence based practice we are all urged to follow. Doyle's, and now Austin's, error seems to be that they confuse evidence based practice with the oxymoronic evidence based purchasing. What evidence, however clear, cannot do is to tell you whether to fund an expensive drug with a modest impact on a widespread, devastating, and previously pharmacologically untreatable disorder, or ask Philip Morris to help reduce the chances of anyone living long enough to develop it. Only emotion can help us there.

A J D Macdonald professor of old age psychiatry King's College London, Lewisham Hospital, London SE13 6LH alastair.macdonald@kcl.ac.uk

Eli Lilly has funded refreshments at countless training events for senior house officers, several lectures for general practitioners, and a few receptions at international conferences in which AJDM has participated. They have also contributed or met his travel expenses and accommodation costs for two conferences in Europe. AJDM does not smoke.

1 Doyle Y. Equity in the new NHS: hard lessons from implementing a local healthcare policy on donepezil. $B M J$ 2001;322:222-4. (28 July.)

\section{Drugs for Alzheimer's disease}

\section{More effective agents are needed}

EDITOR-O'Brien and Ballard in their editorial outlined the approval by the National 
Institute for Clinical Excellence of cholinesterase inhibitors for the treatment of mild to moderate Alzheimer's disease. ${ }^{1}$ We believe, however, there are limitations in the evidence of the efficacy of cholinesterase inhibitors that should be considered.

Pharmaceutical companies have sponsored most of the studies so far, which may lead to overestimation of the effect size. ${ }^{2}$ Many studies have been conducted in selected samples in secondary care, and the drugs may be less effective in the wider population. Most studies used "intention to treat" analyses (all randomised cases are included in the results, whether they completed the study or not) with "last observation carried forward" (including the last observation as the final result). Since people with dementia tend to get worse over time, those leaving a study early will carry forward artificially "better" results. People taking effective doses of cholinesterase inhibitors tend to drop out more often than those in the placebo arm, which leads to overestimation of the treatment effect.

The current standard measure of efficacy in dementia studies is the 70 point cognitive subsection of the Alzheimer's disease assessment scale (ADAS-cog). This and similar measures of cognition may miss some of the effects of the cholinesterase inhibitors and underestimate the true effects of these drugs. The current evidence suggests the numbers needed to treat for a 4 point improvement on the ADAS-cog subscale are four for donepezil, seven for galantamine, and 17 for rivastigmine.

We agree that these drugs have led to a new mood of optimism, but more effective agents may be necessary to deliver the results.

James Warner senior lecturer in old age psychiatry Faculty of Medicine, Imperial College of Science, Technology and Medicine, London W10 6DZ

Rob Butler consultant in old age psychiatry St Margaret's Hospital, Epping CM16 6TN

1 O'Brien JT, Ballard CG. Drugs for Alzheimer's disease. BMJ 2001;323:123-4.

2 Koepp R, Miles SH. Meta-analysis of Tacrine for Alzheimer's disease: the influence of industry sponsors. JAMA 1999;281:2287.

3 Warner JP and Butler R. Alzheimer's disease. In: Barton S, ed. Clinical evidence. Vol 5. London: BMJ Publishing Group, 2001

Guidelines for prescribing cholinesterase inhibitors in Australia are similar to those in UK

EditoR-O'Brien and Ballard discuss the use of cholinesterase inhibitors for the palliation of Alzheimer's disease, in particular mentioning issues of cost effectiveness and rationing. ${ }^{1}$ As a British specialist registrar in geriatric medicine currently gaining experience in Australia, I am interested in the Australian experience of prescribing cholinesterase inhibitors.

In Western Australia geriatric physicians rather than psychogeriatricians manage patients with dementia. Two cholinesterase inhibitors, donepezil and rivastigmine, are licensed by the Pharmaceutical Benefits Scheme. Strict guidelines exist for their prescription" a consultant geriatrician or psychogeriatrician must confirm the diagnosis of Alzheimer's disease, and patients must score between 10 and 24 on the standardised mini-mental state examination; patients who score $\geqslant 25$ but have clinical features of Alzheimer's disease should be evaluated further by the cognitive subsection of the Alzheimer's disease assessment scale (ADAS$\operatorname{cog}$ ). The only exceptions to this rule are patients who received cholinesterase inhibitors on private prescription before December 2000; they may continue with treatment indefinitely, using the Pharmaceutical Benefits Scheme's subsidised prescriptions.

The Pharmaceutical Benefits Scheme allows a six month prescription of donepezil or rivastigmine on a named patient basis. To continue to receive subsidised prescriptions beyond six months, patients must show improvement of $\geqslant 2$ points on the minimental state examination (or a reduction of 4 points on the ADAS-cog), measured at any time over the initial prescription period.

Memory clinics are being established throughout Australia to facilitate the assessment and treatment of patients with cognitive impairment. Although the primary aim of these clinics is to evaluate patients' eligibility for cholinesterase inhibitors, they may also result in a fuller multidisciplinary assessment of patients with dementia.

The Australian guidelines are similar to those outlined by the National Institute for Clinical Excellence. Both guidelines address the question of how to measure response and ensure that patients with advanced dementia and non-responders are not treated unnecessarily. The United Kingdom's guidelines also tackle the problem of when to stop treatment. With time, experience will be gained in the management of other difficult issues, such as how to manage patients who report a clinical response (or whose family does) but who fail to show the required improvement on the mini-mental state examination.

Jane M Noble specialist registrar in geriatric and general medicine

Department of Geriatric Medicine, Royal Perth Hospital, Perth, WA 6000, Australia jane.noble@health.wa.gov.au

1 O'Brien JT, Ballard CG. Drugs for Alzheimer's disease. BMJ
2001;323:123-4. (21 July.)
2 Pharmaceutical Benefits Scheme. Guidelines.
www.health.govau/pbs.

\section{Bacteriotherapy may be useful in treating bacterial vaginosis}

EDITOR-The editorial by Huovinen on bacteriotherapy is a reminder that the use of harmless bacteria to displace pathogenic ones is an alternative to the use of antibiotics for dealing with some infections, particularly those that are recurrent or persistent. ${ }^{1} \mathrm{He}$ points out that this approach is not new: it dates back several decades, but it tended to lapse as potent antibacterial agents were developed.

Nevertheless, recently it has been used with some success to treat recurrent otitis media and prevent recurrences of strepto- coccal tonsillitis. Huovinen considers that bacteriotherapy is a promising approach to the future treatment and prevention of respiratory and gastrointestinal infections. He refers to studies in which the rate and severity of respiratory infections in children have been reduced by giving them milk containing Lactobacillus $G G$, and ulcerative colitis has been treated successfully with non-pathogenic Escherichia coli.

However, looking to the future and not mentioned at all is the possibility of using lactobacilli to treat the most common cause of vaginal discharge - namely, bacterial vaginosis. This occurs in about $10 \%$ of sexually mature women and is a condition in which the normal vaginal flora, dominated by lactobacilli, is displaced by a mixed flora of other bacteria. ${ }^{2}$ It is not trivial because it has been associated strongly with preterm labour and miscarriage and with other conditions including non-gonococcal urethritis in men. ${ }^{3}$

Treatment with metronidazole or clindamycin may be successful. Nevertheless, recurrence is common, and it is sensible to think of replacing the aberrant bacteria with lactobacilli. But strains isolated from dairy sources have been shown to be inappropriate, although they are sometimes used intravaginally by women. ${ }^{4}$ Preparations of Lactobacillus spp for oral ingestion are widely available over the counter. They are sold in some supermarkets as promoters of wellbeing. These are likely to be unhelpful to women with bacterial vaginosis because the lactobacilli are directed at the wrong anatomical site and are of the wrong kind. Vaginal lactobacilli should be used that have been shown to adhere strongly to vaginal epithelial cells and that have other desirable properties. $^{5}$

Unfortunately, this approach to treatment, although logical and evaluable, has not caught the imagination of funding bodies, at least in the United Kingdom, so that basic research has been slow and clinical trials have not been initiated. We hope that a change of attitude will occur and lead to more rapid progress in the future.

David Taylor-Robinson emeritus professor Imperial College School of Medicine, St Mary's Hospital, Winston Churchill Wing, London W2 1NY

Isobel Rosenstein food policy development and scientific secretariat coordinator

Public Health Laboratory Service Headquarters,

London NW9 5DF

irosenstein@phls.org.uk

1 Huovinen P. Bacteriotherapy: the time has come. $B M J$ 2001;323:353-4. (18 August.)

2 Taylor-Robinson D, Hay P. The pathogenesis of the clinical signs of bacterial vaginosis and possible reasons for its occurrence. Int J STD AIDS 1997;8(Suppl.):13-6.

3 Hay PE, Lamont RF, Taylor-Robinson D, Morgan DJ, Ison $\mathrm{C}$, Pearson J. Abnormal bacterial colonisation of the genital tract and subsequent preterm delivery and late miscarriage. BMJ 1994;308:295-8

4 Hughes VL, Hillier SL. Microbiologic characteristics of lactobacillus products used for colonisation of the vagina. Obstet Gynecol 1990;75:244-8.

5 McLean NW, Rosenstein IJ. Characterisation and selection of a lactobacillus species to re-colonise the vagina of women with recurrent bacterial vaginosis. J Med Microbiol 2000*49:543-52 


\section{Antihypertensive treatment and compliance}

\section{Non-adherence should be addressed first}

EDITOR-Nuesch et al showed in their study that electronic monitoring of patient's adherence had no significant effect on ambulatory blood pressure. ${ }^{1}$ Because nonadherence was not more prevalent among patients with resistance to antihypertensive treatment, they concluded that other factors independent of a patient's willingness to adhere are more relevant in explaining failure of treatment in most patients. These results should, however, be interpreted with caution because of possible selection and differential measurement bias that may have occurred in the study.

Patients who accepted inclusion in the study and were therefore monitored for blood pressure and adherence may adhere more to antihypertensive treatments than the general population. We have no information about how many eligible patients refused to participate. Furthermore, after 28 days of study and on the basis of the results of ambulatory blood pressure, more patients became responsive to treatment than became non-responsive $\left(\chi^{2}=2.9, \mathrm{P}<0.09\right)$ $14 / 49(28.6 \%)$ v 8/54 (14.8\%), respectively. It is important to note that the patients were all following a stable treatment regimen. The only interventions were to monitor blood pressure and adherence, which are both recommended to encourage the patients to take the prescribed medication regularly. Therefore, to explain this clinically relevant difference, I believe that the impact of electronic measurement on adherence to treatment was stronger among patients with uncontrolled blood pressure at the entry to the study than among other patients (control group). Considering that adherence was improved in the non-responder group (differential bias) during the study, it is not surprising that the prevalence of nonadherence was similar among responding and non-responding patients before the study.

Reclassification of patients according to the second measure of blood pressure would not have led to a different conclusion. But, as Nuesch et al discussed, interventions to help patients to follow their regimen that improve adherence to but not outcome of treatment are common, particularly among patients with hypertension. ${ }^{2}$

I agree that other factors than patient's adherence, such as physician's noncompliance with current treatment guidelines, can play a part in the treatment failure of some patients. ${ }^{3}$ Nevertheless, in case of insufficient control of hypertension instead of adapted treatment, I still believe that nonadherence should be considered first in most patients.

This strategy is likely to prevent a "folie à deux" (double madness) where the physician's perception of treatment failure results in both, the physician increasing dose or number of drugs and the patient's adher- ence temporarily improving, resulting in drug toxicity.

Jean-Jacques Parienti doctor

Unité de recherche "Epidémiologie et science de l'information," INSERM U444 Faculté de médecine Saint Antoine, 75571 Paris cedex 12, France jjparien@club-internet.fr

1 Nuesch R, Schroeder K, Dieterle T, Martina B, Battegay E Relation between insufficient response to antihypertensive treatment and poor compliance with treatment: prospective case-control study. BMJ 2001;323:142-6. (21 July.)

2 Haynes RB, McKibbon KA, Kanani R. Systematic review of randomised trials of interventions to assist patients to follow prescriptions for medications. Lancet 1996;383-6.

3 Berlowitz DR, Ash AS, Hickey EC, Friedman RH, Glio Gice Kanate manement of pulation. N Engl J Med 998:339:1957-63.

\section{Study was too short and lacked active} intervention

EDITOR-Nuesch et al evaluated the relation between insufficient response to and poor compliance with antihypertensive treatment. ${ }^{1}$ They concluded that non-compliance with treatment is not more prevalent in patients with hypertension that is resistant to treatment, and that non-compliance is not a relevant cause of resistance to antihypertensive treatment.

The data presented in their paper do not support these conclusions, which provide a misleading clinical message. Noncompliance may be equally frequent in patients who are responsive to treatment and resistant ones. This does not, however, indicate that poor adherence to treatment is not an important issue in resistance to treatment. Non-compliance in a patient responsive to treatment suggests that the patient is either overtreated or never needed antihypertensive treatment-the patient has "white coat hypertension." Clinically, it is more important to detect non-compliance in patients resisting treatment because of the potential impact on cardiovascular complications. Nuesch et al do not provide the blood pressure values measured before and after compliance monitoring in all subgroups since blood pressure control is the ultimate goal of the whole intervention. They also do not emphasise that one third of the patients resistant to treatment could have been reclassified to treatment responsive after the introduction of compliance monitoring, which improves compliance and thereby blood pressure control.

We also question the validity of the arbitrarily chosen cut-off point for compliance at $80 \%$. This has often been used in the literature but no evidence is available that this number has any clinical relevance. ${ }^{2}$ The data presented by Nuesch et al indicate that this percentage has no clinical meaning as some patients could be controlled with less than $80 \%$ compliance and others could not In addition, the investigators did not take into account the dynamic aspect of compliance. Patients' compliance often improves immediately before the consultations (white coat compliance). Thus, it is important to analyse the distribution of the days of non-compliance in relation with the corresponding blood pressure measurements.
To assess the relevance of noncompliance in explaining treatment resistance in hypertensive patients, one should try to improve compliance and evaluate the impact of this intervention on blood pressure control, over an observation period of at least six months. This study was too short and lacked an active intervention.

The inherent message provided by Nuesch et al borders on absurdity-it does not matter whether the patient takes his treatment regularly or not. Do we really question the causal relation that should exist between the ingestion of the antihypertensive medication and blood pressure control?

Michel Burnier associate professor Michel.Burnier@chuv.hospvd.ch

H R Brunner professor of medicine Division of Hypertension and Vascular Medicine, Centre Hospitalier Universitaire Vaudois,

Lausanne, Switzerland

1 Nuesch R, Schroeder K, Dieterle T, Martina B, Battegay E Relation between insufficient response to antihypertensive treatment and poor compliance with treatment: prospective case-control study BMI 2001:323:142-6. (21 July.)

2 Haynes RB, Sacjett DL, Gibson ES, Taylor DW, Hackett BC, Roberts RS, et al. Improvement of medication compliance in uncontrolled hypertension. Lancet 1976;i:1265-8.

\section{Pharmacological properties of} antihypertensive drugs research need to be acknowledged

Editor-Nuesch et al suggest that noncompliance with treatment may not be associated with resistance to antihypertensive treatment. ${ }^{1}$ Although there is little evidence on this topic, Burnier et al came to the opposite conclusion in a recent publication. ${ }^{23}$ Their study included 41 hypertensive patients resistant to a regimen including three drugs. Electronic monitoring of compliance alone for two months led to a significant reduction in mean blood pressure from 156/106 $\mathrm{mm} \mathrm{Hg}$ (SD 23/11 $\mathrm{mm} \mathrm{Hg}$ ) to $145 / 97$ $\mathrm{mm} \mathrm{Hg}$ (SD 20/15 mm Hg, P $<0.01)$. But this study was small and did not have a control group.

Nuesch et al could have strengthened their conclusions by providing some additional information. Side effects of treatment may influence compliance but were not considered in the comparisons of compliance and non-compliance or of response and non-response. It is also important to know whether both study groups were similar with regard to the type and number of antihypertensive drugs being used. Non-compliance with long acting medications may affect treatment effect much less than shorter acting agents where the timing of doses may be more important.

The study was too short and too small to come to any firm conclusions about the relation between compliance and blood pressure control. The methods of measuring compliance and blood pressure are not typical of clinical practice and may have induced powerful effects in some patients, thereby removing any relation between compliance and blood pressure control. Future studies should acknowledge the different pharmacological properties of various antihyper- 
tensive drugs. Investigators should attempt to define what level of compliance is required to achieve a desired effect of treatment. Electronic monitors can provide valuable additional data that include the exact timing of doses and inter-dose intervals. ${ }^{4}$ Although methodologically challenging, analysis of such data might provide more detail on the extent and nature of non-compliance and its relation with blood pressure control.

We are currently recruiting 350 patients with uncontrolled essential hypertension for a primary care based randomised controlled trial on the effectiveness of nurse-led and patient-centred compliance counselling, funded by the Medical Research Council. We will use electronic monitors for 8-12 months after an initial two month run-in period before the intervention. We hope to be able to contribute new data on the relation between medication compliance and blood pressure control.

Knut Schroeder MRC training fellow in health services research

k.schroeder@bristol.ac.uk

Alan Montgomery MRC training fellow in health services research

Division of Primary Health Care, University of Bristol, Bristol BS8 2PR

Shah Ebrahim professor in the epidemiology of ageing Department of Social Medicine, University of Bristol

1 Nuesch R, Schroeder K, Dieterle T, Martina B, Battegay E Relation between insufficient response to antihypertensive treatment and poor compliance with treatment: a prospective case-control study. BMJ 2001;323:142-6. (21 July.)

2 Ebrahim S. Detection, adherence and control of hypertension for the prevention of stroke. A systematic review. Health Technology Assessment 1998;2(11): i-iv, 1-78.

3 Burnier M, Schneider MP, Chiolero A, Stubi CLF, Brunner $\mathrm{H}$. Electronic compliance monitoring in resistant hypertension: the basis for rational therapeutic decisions. Hypertens 2001;19:335-41.

4 Metry JM. Measuring compliance in clinical trials and ambulatory care In: Metry J-M, Meyer UA eds. Drug regimen compliance issues in clinical trials and patients. Drug ment Chichester: Wiley, 1999:1-21.

\section{Author's reply}

EDITOR-Parienti and Burnier and Brunner ask about differential effects of compliance monitoring on blood pressures in subgroups in our study. This point is well taken, and blood pressure improves more significantly in patients who are resistant to treatment compared with those who are responsive. A study by Burnier et al, published after finalisation of our manuscript, describes that clinical readings of blood pressure improved in some of 41 treatment resistant patients on compliance monitoring. ' Yet, in our and Parienti's additional analysis and the study by Burnier et al, readings of most patients remain unchanged or resistant to treatment even after monitoring compliance.

We agree that use of binary data may reduce statistical power, but it is general clinical practice and was therefore presented in our study. Analysis not presented in the paper shows that blood pressure broken down as a continuous variable versus response to or compliance with treatment does not change our results.
Burnier and Brunner wonder why patients categorised as non-compliant had normal blood pressures. Continuous monitoring of blood pressure was performed before and after assessment of compliance in all our patients, and no patients with "white coat hypertension" were classified as resistant to treatment. Most patients categorised as non-compliant were, however, partly compliant, similar to virtually all studies on this issue. We agree with Schroeder et al that partial compliance may induce sufficient therapeutic responses depending on the pharmacological properties of antihypertensive drugs. Therefore a cut-off point of $80 \%$ for compliance has been used in the hypertension literature and in our study. ${ }^{2}$ Normalisation of blood pressure is common in treatment with placebo or after discontinuation of longstanding treatment. ${ }^{3}$ Regression to the mean occurs in any observational collective and therefore requires a control group. The study by Burnier et al did not include a control group. ${ }^{1}$

We agree with Burnier and Brunner that antihypertensive treatment and adequate compliance are pivotal in controlling blood pressure. They are, however, wrong in assuming that our paper gives a misleading message. Our main point is that compliance rates in hypertensive patients who are resistant to treatment are better than often assumed. Burnier et al observed better compliance rates than we did-above $90 \%$-yet most of their patients remained resistant to treatment despite compliance monitoring and became responsive only after treatment had been adapted.

We agree with Parienti, Schroeder et al, and Burnier and Brunner that compliance and response to treatment fluctuate. Therefore we selected patients having stable antihypertensive treatment and monitored blood pressure continuously twice to ascertain adequate classification of the response to treatment. Our study, like any other study, glimpses only a specific period of the patients' lives.

Edouard Battegay assistant professor of internal medicine

ebattegay@uhbs.ch

Reto Nüesch senior registra

Benedict Martina head of medical emergencies

Thomas Dieterle senior fellow

Outpatient Department and Hypertension Clinic of Internal Medicine, University Hospital, CH-4031 Basel, Switzerland

\section{A longer version of this letter appears} on bmj.com

1 Burnier M, Schneider MP, Chioléro A, Fallab Stubi CI Brunner HR. Electronic compliance monitoring in resistant hypertension: the basis for rational therapeutic decisions.J Hypertens 2001:19:335-41.

2 Hill MN. Adherence to antihypertensive therapy. In: Izzo 2 Hill MN. Adherence to antihypertensive therapy. In: Izzo
JL, Black HR, eds. Hypertension primer. The essentials of high blood pressure (American Heart Association). Baltimore: Lippincott, Williams and Wilkins, 1999: 348-51.

3 Preston RA, Materson BJ, Reda DJ, Williams DW. Placeboassociated blood pressure response and adverse effects in the treatment of hypertension. Arch Intern Med 2000;160:1449-54.

4 Aylett M, Creighton P, Jachuck S, Newrick D, Evans A. Stopping drug treatment of hypertension: experience in 18 British general practices $B r$ J Gen Pract 1999;449: 18 British general practices. Br J Gen Pract 1999:449: $977-80$.

\section{No blame should be apportioned in corporate failure}

Editor-Hey and Chalmers express concern about the Griffiths report and the prolonged suspension of two paediatricians at North Staffordshire Hospital. ${ }^{1}$ I share their concerns.

The Griffiths inquiry faced several difficulties.

Firstly, few researchers, however meticulous, can instantly produce all the relevant data and records from projects completed some years earlier.

Secondly, the resources and range of expertise needed to conduct such a complex investigation were (and still are) seriously underestimated.

Thirdly, Griffiths's team was not ideally qualified for such a complex task.

Fourthly, there was no framework of good practice to guide them-unfortunately, this is still the case.

Perhaps the responsibility for failures of corporate systems is more widespread than implied by Hey and Chalmers. Politicians, the civil service, NHS management, and the healthcare professions had all either not recognised the speed of change in public expectations regarding quality, safety, and transparency in public services or not implemented a system that could respond appropriately to complex complaints-and, in particular, to serial, orchestrated allegations of misconduct or incompetence. ${ }^{2}$

The chief medical officer does understand the need to implement a culture in which no blame is apportioned. ${ }^{3}$ There are encouraging signs that the secretary of state does too. Could we apply this principle to the North Staffordshire events? We might, if two lessons-one general and one specificare learnt. The general lesson is that procedures for investigating complaints and conducting inquiries must be better planned from the start, with appropriate membership, resources, and procedures, so that just one investigation is undertaken, instead of the series of reviews that was needed at Stoke.

The specific lesson is that complaints in respect of child protection work are different from other NHS complaints. Procedures must be re-examined in the light of North Staffordshire. "Working together" requires health and social services to work together, so they share responsibility for problems, and it would be sensible for complaints to be investigated jointly.

David Hall professor of community paediatrics Institute of General Practice, Community Sciences Building, Northern General Hospital, Sheffield S5 7AU

d.hall@sheffield.ac.uk

1 Hey E, Chalmers I. Open letter to the chief medical officer. BMJ 2001;323:280-1. (4 August.)

Marcovitch H. Diagnose and be damned. BMJ 1999;319:1376.

3 Department of Health. A commitment to quality, a quest for excellence. London: $\mathrm{DoH}, 2001$ 


\section{An unmerciful end}

\section{Decisions not to resuscitate must not be} left to junior doctors

EDITOR-Soper's harrowing description of an elderly woman's "unmerciful end" after cardiopulmonary resuscitation by a team of paramedics raises many ethical issues about what constitutes a dignified, natural death.

My research group runs training courses in communication skills for healthcare professionals working in oncology. We have been dismayed by the number of specialist registrars and senior house officers working at a large, famous cancer institution who have asked us recently for help about discussing "do not resuscitate" decisions with patients who are dying. The BMA guidelines recommend that consultants should have ultimate responsibility for this onerous and sometimes deeply distressing task, but in reality it falls on their juniors.

As we worked with our team of simulated patients (actors) on different scenarios that the doctors had had to confront, the actors expressed incredulity that this should even be a topic for discussion with patients. Who in their right mind would consider cardiopulmonary resuscitation to be a reasonable, humanitarian act to perform on a patient, whatever age, with widespread metastatic disease nearing the end of his or her life?

Central to the ethos of my research group is the premise that patients have a right to honest information, to discuss their concerns and worries about death, and to choose where they die, with the appropriate care and support. I do not think that this should include hypothetical discussions about a management that most would agree to be inhumane. Any armchair ethicist who suggests that these conversations should take place with dying people should try doing it.

The guidelines and directives might well be appropriate for some situations, but I wonder just whose interests are really being served. If it is indeed necessary to have do not resuscitate preferences recorded in the hospital notes then such sensitive and distressing issues should not be left to untrained junior doctors.

Lesley Fallowfield director

CRC Psychosocial Oncology Group, School of Biological Sciences, University of Sussex, Brighton BN1 9QG

L.Fallowfield@biols.susx.ac.uk

1 Soper RH. An unmerciful end. BMJ 2001;323:217. (28 July)

\section{Society must show respect for people} who are dying

EDITOR-A true mark of a society is how it deals with its dying. As Soper's story illustrates, we sometimes do very badly. ${ }^{1}$ In her rapid response to Soper's piece ${ }^{2}$ [published here as the letter above] Fallowfield writes, "Who in their right mind would consider [cardiopulmonary resuscitation] a reasonable, humanitarian act to perform on a patient, whatever age, with widespread metastatic disease nearing the end of [his or her] life?"

I agree wholeheartedly with Fallowfield. There are some things that professional training and experience teaches us that do not need to be discussed with patients. But this view is not held by everyone. Contributing to the discussion after an editorial on do not resuscitate orders, Roger Goss, director of Patient Concern, wrote, "Do not resuscitate orders at any age, without discussion, are unethical. Eradicating this practice in the NHS requires legislation-full stop."3

If this view becomes more widespread Soper is right to worry about the lurking legal profession, and there will be many more relatives denied the right to say goodbye to their loved ones in peace.

Neville W Goodman consultant anaesthetist Southmead Hospital, North Bristol NHS Trust, Bristol BS10 5NB

Nev.W.Goodman@bris.ac.uk

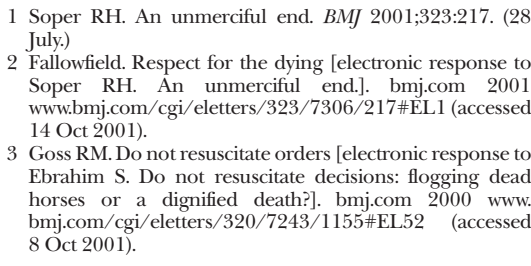
8 Oct 2001).

\section{Office of NHS cancer screening programme misrepresents Nordic work in breast screening row}

EdiToR-In Mayor's news story in the issue of 27 October the office of the NHS cancer screening programme in the United Kingdom misrepresents our research entirely. The office says that our findings of more aggressive treatment of breast cancer among screened women are based on only two studies, classified as poor quality. They are not. Numbers of mastectomies as well as numbers of tumourectomies increase when women are screened. This finding is consistent and is based on all four of the seven screening trials that have published data on this, including the two medium quality trials from Canada and Malmö. ${ }^{2}$

The office also incorrectly notes that we did not investigate whether more aggressive treatment was beneficial since we published extensive mortality data. ${ }^{2}$ Furthermore, it is wrong to say that our conclusion about the lack of benefit of mammography comes from an analysis of the two trials of medium quality. Our results for overall mortality and for deaths ascribed to any cancer, including breast cancer, are consistent and relate to both medium quality and poor quality trials. There was not even a trend towards a reduction in all cause mortality or all cancer mortality.

The office notes that many researchers would classify all seven studies as of similar quality. This statement is astonishing. We have shown important differences in quality and that the trials from Edinburgh and New York are flawed. For this reason, the editors from the Cochrane Breast Cancer Group suggested that we omitted the results from these two studies from our analyses, to which we agreed. There is now ample evidence from four large studies that lack of proper quality assessment of the individual trials in systematic reviews leads to grossly exaggerated claims of benefit. ${ }^{4}$

Accordingly, we have shown that the estimate for mortality from breast cancer in the poor quality trials is much lower and significantly different from the estimate based on the medium quality trials. ${ }^{23}$ To disregard this finding is bad science. If anybody disagrees with our assessments of quality, we would like to know exactly on what grounds. However, to avoid more misquotations, we recommend our critics read our full report first (available at http://image. thelancet.com/lancet/extra/fullreport.pdf).

When the office claims that there is clear evidence of the benefit for mammography when all seven studies are combined, it overlooks not only that some studies are flawed but also the finding that mortality from breast cancer is a misleading and biased outcome measure that favours screening, as we and others have documented. ${ }^{235}$

Thus, all the statements offered by the office of the NHS cancer screening programme are misleading and misrepresent our research. This is depressing. It is a disservice to women's need for honest information, and it also underlines the importance of Richard Horton's statement in his commentary that "The implications for women and policy makers are substantial and require careful reflection and discussion." ${ }^{\prime 6}$ To crown it all, the statements are anonymous attacks on scientific work. This is improper and unfair since there is no accountability. Who gave these statements?

Peter C Gøtzsche director

Nordic Cochrane Centre, Rigshospitalet, DK-2100 Copenhagen $\emptyset$, Denmark pcg@cochrane.dk

Competing interests: None declared.

1 Mavor S. Row over breast cancer screening shows that scientists bring "some subjectivity into their work" $B M$ 2001.329.956. (27 October)

Cochrane review on screening for

Olsen O, Gøtzsche PC. Cochrane review on screening for breast cancer with mammography. Lancet 2001;358

3 Olsen O, Gøtzsche PC. Screening for breast cancer with mammography. Cochrane Database Syst Rev 2001;(4):

4 Jüni P, Altman DG, Egger M. Systematic reviews in health care: Assessing the quality of controlled clinical trials. BMJ 2001;323:42-6. (7 July.)

5 Early Breast Cancer Trialists' Collaborative Group. Favourable and unfavourable effects on longterm survival of radiotherapy for early breast cancer: an overview of the randomised trials. Lancet 2000;355:1757-70.

6 Horton R. Screening mammography-an overview revisited. Lancet 2001;358:1284-5.

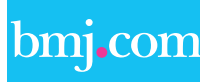

Rapid responses

Correspondence submitted electronically

is available on our website 